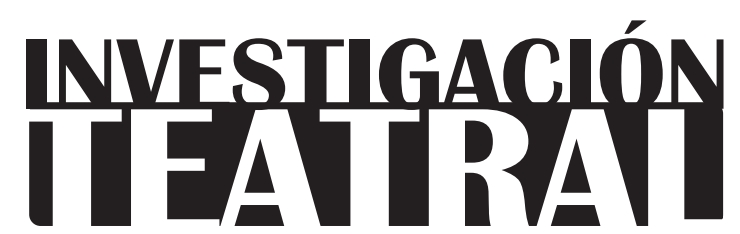

Revista de artes escénicas y performatividad

Vol. 9, Núm. 13

abril-septiembre 2018

Segunda época

ISSN impreso: 1665-8728

ISSN electrónico: 2594-0953

Universidad Veracruzana

\title{
Soberanía estallada: Memorias de Malvinas en Campo minado de Lola Arias
}

\author{
Verónica Perera*
}

\footnotetext{
* Departamento de Humanidades y Artes, Universidad Nacional de Avellaneda, Buenos Aires, Argentina.

e-mail:veronic.perera@gmail.com
}

Recibido: 01 de junio de 2017

Aceptado: 28 de noviembre de 2017 


\title{
Soberanía estallada: Memorias de Malvinas en Campo minado de Lola Arias
}

\section{Resumen}

El trigésimo aniversario de la guerra de Malvinas en el 2012 apareció como huella del pasado y fue recuperado en Argentina por la imaginación de una generación joven de dramaturgos y dramaturgas. Según Rosana Guber, este conflicto bélico operó históricamente como metáfora de la nación; sin embargo, el presente artículo argumenta que la obra Campo minado de Lola Arias subvierte esa metáfora. Asimismo, propone que esta obra estrenada en Brighton, Inglaterra, en mayo del 2016 y seis meses más tarde en Buenos Aires, descentra la noción de comunidad nacional, pues, mediante la actuación de seis excombatientes (tres argentinos, dos ingleses y un gurkha) y una historia basada en sus testimonios, narra el conflicto bélico sin tonos épicos y explora la cuestión de la soberanía nacional, aunque sin silenciar sus efectos sobre los cuerpos en la guerra. Finalmente, sugiere que la obra de Arias crea un espacio plurinacional y multilingüe, donde surgen nuevas imágenes y memorias sobre la guerra de Malvinas, atravesadas hoy por la experiencia común, pero también por el disenso y el conflicto entre los enemigos de entonces.

Palabras Clave: teatro documental, Lola Arias, Malvinas, Londres, Buenos Aires.

\section{Bursted Sovereignty: Falklands Memories in Campo minado (Minefield) by Lola Arias}

\begin{abstract}
The thirtieth anniversary of Malvinas (Falklands) War in 2012 became a trace of the past, recovered by a young generation of playwrights. According to Rosana Guber, that war has worked as a metaphor of the nation, but this paper argues that Campo minado (Minefield) by Lola Arias subverts that metaphor. The play was premiered in Brighton, England, on May 2016 and six months later in Buenos Aires. It is based on veterans' testimonies who actually take part in the show (three Argentineans, two English, one Gurkha) and by these means the play achieves to decenter the notion of national community. The article discusses how Minefield narrates the war without epic tones and explores the question of national sovereignty, but without silencing its effects on the bodies at war. Finally, the paper suggests that Arias' play creates a plurinational and multilingual space from where new images and new memories of Malvinas emerge. These images and memories are permeated with the common experience of the enemies at that time, but also with the conflict and dissent between them.
\end{abstract}

Keywords: documentary theater, Lola Arias, Malvinas, Falklands, London, Buenos Aires. 


\section{Soberanía estallada: Memorias de Malvinas en Campo minado de Lola Arias}

$\mathrm{E}$ trigésimo aniversario de la guerra de Malvinas en el 2012 apareció como huella del pasado - usando la expresión de Maurice Halbwach-, recuperada en Argentina no solo por la gestión diplomática y por organizaciones militantes de excombatientes, sino también por la imaginación de una generación joven de dramaturgas y dramaturgos. Treinta años después, el teatro independiente se hizo eco del teatro de operaciones militares de 1982 y se adaptaron ficciones literarias fundantes sobre la guerra, como Los Pichiciegos de Rodolfo Fogwill (1983) o Las Islas de Carlos Gamerro (1996). ${ }^{1}$

Campo Minado de Lola Arias es también un producto de ese contexto memorial. Esta puesta en escena fue encargada por dos festivales de teatro en Inglaterra, y luego de tres años de trabajo en Buenos Aires y en Londres, se presentó primero en el Festival de Brighton, el 28 de mayo de 2016, y casi seis meses más tarde en el Centro de Artes Experimentales de la Universidad Nacional de General San Martín en Buenos Aires.

La obra de Arias no inaugura el teatro documental sobre Malvinas. Cuatro años antes, por ejemplo, Julio Cardoso había escrito y codirigido Islas de la Memoria. Historias de guerra en la posguerra, desde el Observatorio Malvinas de la Universidad Nacional de Lanús

1 Mariana Mazover y Diego Quiroz escribieron, respectivamente, Piedras dentro de la Piedra y Los Tururú a partir de la novela picaresca Los Pichiciegos (1983) de Rodolfo Fogwill. Carlos Gamerro adaptó su propia ficción, Las Islas (1996), y la puso en escena con el mismo nombre bajo la dirección de Alejandro Tantanian. Mariano Saba ganó con Lógica del Naufragio el concurso realizado por el Instituto Nacional del Teatro. 
(una obra también basada en testimonios personales de excombatientes, ${ }^{2}$ pero representados por actores profesionales). Como buena parte de la dramaturgia $-\mathrm{y}$ de la producción audiovisual - sobre Malvinas, la pieza de Cardoso insiste en la patria como fundamento para la guerra, y persevera, con símbolos tan inequívocos como el himno o la bandera, en narrarla como gesta nacional. ${ }^{3}$ El dramaturgo habla de su obra explícitamente como un homenaje, como un "reconocimiento al sacrificio enorme que hicieron quienes combatieron" (Santoro cit. en Perera y Diz, 2016).

Campo Minado, entonces, no inaugura una dramaturgia sobre Malvinas basada en testimonios de excombatientes. Sin embargo, Arias inicia un tipo de teatro documental que al desplazar los ejes que generalmente organizan las narraciones sobre la guerra, crea nuevas imágenes y nuevas memorias sobre el conflicto bélico de 1982. Según Rosana Guber, la guerra solo mostró su eficacia, pero Malvinas funcionó como metáfora de la nación desde el siglo XIX. Pertenecientes al dominio territorial argentino solo de manera ideal, invadidas por el gigante colonial desde 1833, las Malvinas preservaron la "capacidad de encarnar la 'plena argentinidad' mucho más que cualquier otro símbolo que, dentro del continente, hubiera caído en el fuego cruzado de los enemigos" (Guber 164-165). Siempre en clave filial o familiar, profundiza Guber, Malvinas operó como metáfora de continuidad nacional, como símbolo construido de comunidad de pertenencia; símbolo que habla de las relaciones entre los sujetos, entre éstos y su Estado y con otros Estados.

Campo Minado, en cambio, subvierte dicha metáfora de Malvinas, desbarata su capacidad para funcionar como emblema de la nación. Estalla la cuestión de la soberanía sobre las Islas y sus disputas (aunque sin esconder los escombros de ese estallido). Igual que su dramaturga y directora, cuya producción despliega argumentos y espectáculos en múltiples lugares, ${ }^{4}$ Campo Minado combate las muy vapuleadas fronteras nacionales para esbozar una comunidad otra.

2 Además de correspondencia entre los soldados y sus familias durante la guerra, la obra también se basa en testimonios personales de excombatientes y de familiares de caídos en combate (Perera y Diz, "Memorias del pasado").

${ }^{3}$ Pienso, por ejemplo, en piezas teatrales como Mares de Piedra de Roxana Aramburú o Grietas de Lola Banfi, ganadoras del concurso Nuestro Teatro 2015, en homenaje a Teatro Abierto, presentadas en el Teatro del Picadero. La quintaesencia de este tipo de narración audiovisual es la reciente Soldado argentino solo conocido por Dios, del joven cineasta Fernández Engler, estrenada el 6 de abril del 2017.

${ }^{4}$ Arias trabaja simultáneamente en y a partir de varios países. Sus obras, filmes e instalaciones fueron presentadas en festivales internacionales en Alemania, Francia e Inglaterra y en espacios de arte de Buenos Aires, Los Ángeles, Mineápolis y Chicago. 
A lo largo del "experimento social" en el que transcurre la pieza, ${ }^{5}$ los seis excombatientes que pueblan el escenario - tres argentinos, dos ingleses, un gurkha- descentran la noción de comunidad nacional y crean un espacio de pertenencia atravesado por el disenso y la experiencia común, por el conflicto y la vivencia semejante, por el recuerdo traumático y la fuerza para rememorarlo, por el dolor y la potencia. Crean un espacio multilingüe y plurinacional desde donde se advierte la imposibilidad de una memoria única sobre Malvinas. Surgen así otras maneras de pensar y de narrar la guerra sin tonos épicos, interrumpiendo los anclajes nacionales y apartando, aunque sin silenciarlo, el reclamo por el dominio territorial y la disputa por el gobierno de las Islas.

\section{"Estoy ahí, con el enemigo, contándonos historias" (o sobre el teatro documental) ${ }^{6}$}

Entre el teatro documental y el biodrama, entre el testimonio y la ficción, Campo Minado retoma muchos de los procedimientos escénicos que Arias había utilizado en Mi vida después (una obra donde los actores recuerdan y actúan la vida de sus propios padres durante la última dictadura cívico-militar en Argentina) y en su texto gemelo sobre la dictadura chilena, El año en que nací. Recurriendo a la biografía personal, la historia colectiva o incluso a la "imaginación sociológica", según el libro homónimo de C. Wright Mills (1959), así como a documentos públicos y privados, Campo Minado reconstruye la experiencia de seis veteranos. Los 16 capítulos del texto dramático abarcan ininterrumpidamente el recorrido que va desde la reconstrucción de las entrevistas iniciales para la obra ("Audiciones") hasta la historia sociopolítica de las Islas narrada simultáneamente por un argentino y un inglés ("Malvinas"). La obra recupera experiencias de estos veteranos en la guerra: antes ("Convertirse en soldado", "Camino a la guerra"); durante ("El hundimiento del Belgrano", "Jets", "Mount Harriet", "Ultimo día de la guerra"), y después de su estancia en el territorio malvinense ("Vuelta a Casa", “Terapia”, "Por el Mundo"). La puesta en escena deja ver entonces el proceso creativo que la generó, al tiempo que reflexiona sobre el mismo. Revela, por ejemplo, escenas, canciones, formas de referirse al conflicto bélico que fueron excluidas del texto final. "Durante los ensayos..." es una frase que el público escucha en reiteradas ocasiones, evocando algunos de los dilemas y encrucijadas del proceso dramático dirigido por Arias.

${ }^{5}$ La propia Arias se refiere a sus obras como "experimiento social" (Arias y Kan, "Lola Arias"). Las páginas siguientes explican por qué.

${ }^{6}$ Todas las citas corresponden al registro audiovisual de la presentación de la obra en Inglaterra en 2016, cedido por la directora a la autora de el presente texto. 
Los actores de Campo Minado no son profesionales. Son los veteranos mismos quienes narran en escena, individual y grupalmente, sus propias vivencias de guerra. Colaborativamente, cada cuerpo relata también lo sucedido a otros. Dado que no hablan el idioma de sus otrora enemigos, la narración transcurre fundamentalmente en español y en inglés con traducciones subtituladas en el escenario. ${ }^{7}$ Campo Minado es un encuentro de cuerpos en 2016 afectados sensiblemente por sus enemigos de 1982; un colectivo sensible que, como dice en su presentación el antes soldado - hoy jardinero y campeón de triatlón- Marcelo Vallejo, "entiende muy pocas palabras pero en los gestos y las miradas [se] puede entender lo que [se] quieren decir".

Con un texto dramático escrito por Arias en colaboración con los seis excombatientes, cada actor reconstruye en escena tanto experiencias propias como ajenas, de sus pares allí presentes. Los veteranos devienen actores, pero no solo en el escenario: devienen también autores del texto dramático (co-escrito entre ellos y Arias) y por lo tanto de sus propias memorias. Dejan de ser así "las víctimas": decidieron, por ejemplo, no incluir en la obra escenas de torturas creadas y ensayadas durante el proceso de producción "porque nadie quería hacer el rol de víctima", explica el antes soldado - hoy abogado- Gabriel Sagastume. Dejaron de ser también "los héroes de Malvinas" homenajeados y formulados por otros. Estos veteranos devienen actores porque toman la palabra sobre la guerra y la vuelven dramática y bella para un público deseoso de escucharla. "Mi mujer me llama 'el monotema'. Me doy cuenta de que hablando de la guerra arruino todas las reuniones", confiesa al presentarse Gabriel Sagastume.

Campo Minado permitió a Sagastume y a sus compañeros crear memorias de la guerra transformando el tono del relato anterior. Les permitió hacerse dueños de las condiciones de producción (y de recepción) de su propio testimonio. No se trata ya de "una conversación que arruina reuniones", ni tampoco de una gesta, una epopeya o una causa nacional. Tampoco se trata de una guerra condenada al olvido por su asociación con la última dictadura argentina. Campo Minado es un "experimento social" donde el escenario se vuelve un espacio de encuentro de cuerpos sensibles que toman la palabra sobre la guerra, junto con sus otrora enemigos, para producir relatos multisituados y necesariamente conflictivos,

7 En varias escenas, el antes gurkha, hoy empleado de seguridad, Sukrin Rai, trae el universo cultural y artístico de Nepal en su originario nepalí. Estas intervenciones poéticas no se traducen. "Siempre se pierde algo en la traducción. Es mejor dejarlo en un lenguaje poético abierto, para no perder riqueza o valor cultural", dijo Arias en una entrevista realizada por Gonzalo Aguilar que siguió a la representación de la obra el 2 de diciembre de 2016 en el Centro de Artes Experimentales de la Universidad Nacional de San Martín (UNSAM) en Buenos Aires. 
generando un testimonio dirigido a un público grande. ${ }^{8}$ El acontecimiento implica "una alteridad en diálogo" que, como escribe Jelin, es una de las condiciones que hacen posible el testimonio.

\section{Multimedia: relatos multiescalares y multisituados (o sobre el disenso y la memoria)}

Siguiendo con los procedimientos escénicos de Mi vida después y El año en que nací (y en la línea del teatro documental), ${ }^{9}$ Campo Minado es, entre otras cosas, un montaje de documentos públicos y privados. Pero a diferencia del teatro documental "clásico" (sistematizado por Peter Weiss en 1968), en la obra de Arias los documentos públicos alojan también lo íntimo.

Además de su valor histórico, los documentos públicos se utilizan como recursos para narrar lo singular de la biografía y la intimidad de la vivencia, como por ejemplo las fotos y videos de archivos de las Fuerzas Armadas argentinas y británicas que retratan individual y grupalmente a los soldados (imágenes del crucero General Belgrano y del transatlántico Canberra), las triunfalistas tapas de algunas revistas argentinas (como la bien conocida "Seguimos Ganando" de Gente), o incluso algunos videos del fervoroso apoyo popular a la guerra el 2 de abril en Plaza de Mayo, entre otras propagandas oficiales.

Todos estos archivos aparecen en la obra como certificados históricos que brindan información y elaboran el contexto sociopolítico, además de representar espacios donde se alojan pensamientos difíciles de compartir y sentimientos incómodos que marcaron la vida en la guerra. Con estas imágenes, los veteranos reconstruyen acontecimientos importantes del conflicto bélico: la toma de la Casa de Gobierno en Puerto Stanley el 2 de abril, o el hundimiento del General Belgrano o la maratónica campaña televisiva argentina para recaudar fondos que nunca llegaron a destino. Pero también comparten a partir de ellas, por ejemplo, los motivos (nada heroicos) que los llevaron a unirse a las Fuerzas Armadas: "Para escaparme de casa a los dieciséis", cuenta el antes marino inglés - hoy maestro de niño/as con problemas de aprendizaje-, Lou Armour; o la fantasía de "viajar a playas caribeñas con palmeras", explica el hoy sicólogo David Jackson; o simplemente porque "yo sí quería ser soldado" confiesa el argentino Marcelo Vallejo.

Las fotografías acomodan recuerdos - a veces narrados, a veces actuados - de terror

${ }^{8}$ Fue notable la cantidad de público que no pudo entrar a las funciones de noviembre y diciembre de 2016, en el Centro de Artes Experimentales de la UnSAm en Buenos Aires.

9 Ver Sabugal Paz, "Teatro documental". 
y de alivio, de desesperación y de consuelo. Desde las náuseas a bordo hasta la fiesta de los concursos de canto, rematando con los performances travestidos al compás de la Banda de la Marina Real (recreados en la puesta en escena con el striptease travestido de David Jackson), los veteranos rememoran y reconstruyen un repertorio sensible, complejo y variado.

Algunos de los documentos proyectados son inequívocamente privados y enmarcan intimidades. La carta que Gabriel Sagastume escribió a Florencia (quien en aquel momento era su novia y ahora su esposa), le permite hablar del tedio de la espera en la guerra mientras "nada pasa realmente". La proyección del diario íntimo que Lou Armour escribió durante los ensayos en Buenos Aires, confirma al público que Campo Minado reabrió en los veteranos-actores memorias traumáticas difíciles de elaborar, como resultaba previsible. "Algunas preguntas me trajeron recuerdos del pasado lejano; cosas de las que nunca había hablado. No podía dormir, tenía flashbacks, mi mente se apagaba”, confiesa Lou Armour en escena y comparte con el público su decisión de consultar un sicólogo. Algunos documentos son auditivos: como los discursos que inauguraron y concluyeron la guerra en Plaza de Mayo y en el Parlamento inglés y que acompañan, respectivamente, los performances de Sagastume y de Armour con las máscaras de sus líderes, Leopoldo Galtieri y Margaret Thatcher.

La puesta en escena interviene la forma - o la escala - de los documentos utilizados: aparecen siempre proyectados sobre el telón de fondo en tamaño mural, y muchas veces se ilumina en el escenario al dispositivo y al actor que los proyecta y agranda. Así se evocan las múltiples escalas que el texto dramático explora. Desde una reconstrucción crítica del contexto sociopolítico y de los acontecimientos fundamentales, hasta la impugnación al (sin)sentido de la guerra; desde los traumas individuales hasta los vínculos malheridos; desde el entrenamiento físico hasta la vida cotidiana del soldado; desde el hambre y el frío hasta el canto y el striptease travestido para evadirse de la guerra..., la obra de Arias visibiliza matices que interrumpen las claves que suelen organizar las narraciones sobre Malvinas.

Lo matizado y lo multiescalar se complementa, además, con lo multisituado: los relatos se construyen simultáneamente desde situaciones diferentes pero igualmente valoradas; las memorias se recuperan, sincrónicamente, desde posiciones contrapuestas. Surge así una narración atravesada por el disenso y el conflicto transformado: puntos de vista otrora enemigos se legitiman en una misma escena y se integran en una familia de relatos paralelos. Me detengo en dos ejemplos: mientras el argentino Rubén Otero recrea el trauma de cómo sobrevivió al bombardeo del crucero General Belgrano, el inglés Lou Armour rememora el alivio que sintió al saber del hundimiento. El argentino recuerda las 41 horas a bordo de una balsa, intentando no dormirse junto a otros 21 tripulantes y la mitad de su 
cuerpo congelado cuando llegó el rescate del destructor Bouchard. Concluye la escena con un poderoso y catártico solo de batería, ${ }^{10}$ al grito de "i323 muertos!" (la mitad de todos los caídos en la guerra) y “iMalvinas!". El inglés interrumpe la escena para legitimar en tono firme y sereno su sentimiento de alivio: si bien el Belgrano estaba fuera de la zona de exclusión establecida por Inglaterra y se estaba yendo al momento del bombardeo, era una amenaza real y podría haber dado la vuelta para atacarlos.

Otro ejemplo: la inclusión de Sukrin Rai entre los actores habilita al texto dramático de Arias a degradar y celebrar, simultáneamente, la figura de los ghurkas. Para los rumores argentinos recuperados y narrados por Marcelo Vallejo, los ghurkas son "tristemente célebres asesinos", quienes "despedazaron cuerpos" luego de "matar a 300 argentinos" en Goose Green, y hasta "se comieron las orejas" que amputaron a sus enemigos.

A esta escena le sigue otra que recrea un ficcionalizado reality show, dirigido por un ficcionalizado conductor de Tv, actuado por Lou Armour. Marcelo Vallejo y Sukrin Rai se encuentran como invitados en un set televisivo, no sólo para confrontar retratos de los gurkhas sino también para cotejar sus acciones violentas del pasado con los sentimientos amables y transformados del presente. El personaje del conductor introduce a Sukrin como parte de los "buenos servidores de la corona británica por más de 200 años", quienes entregaron "50,000 vidas por Inglaterra durante la Primera y la Segunda Guerra Mundial". Se trata, dice, de "guerreros nepaleses famosos por su habilidad con el cuchillo, el famoso kukri", quienes tienen una "aterradora reputación que los acompañó hasta las Islas Falkland". Invita luego a Sukrin a relatar como "salvó" a un oficial argentino -a quien años más tarde encontró en Buenos Aires durante los ensayos de la obra- porque "capturar es mejor que matar". Si la guerra hubiera durado un solo día más, dice el conductor del reality, estos veteranos se hubieran encontrado e intentado matarse en el campo de batalla de Mount William. Hoy, Marcelo Vallejo ya no quiere "cagar a trompadas a un gurkha", sino más bien "tomarse una cerveza con Sukrin". El antes guerrero cierra la escena solo en un escenario despojado y dulcemente iluminado dedicándole una suave canción nepalí a Vallejo.

Todo en la obra de Arias aparece con esta perspectiva multisituada; hasta la soberanía sobre las Islas, que "no se discute". Pero la cuestión tampoco se oculta "bajo un paraguas", como la expresión que reflejaba la política oficial sobre Malvinas durante el gobierno menemista (1989-1999). Campo Minado no esconde ni el malestar ni la pérdida que la soberanía disputada causa todavía hoy: la obra da lugar al fuego cruzado de acusaciones mutuas y aloja reclamos opuestos y legitimaciones confrontadas, tal como se describe en el apartado siguiente.

${ }^{10}$ El catártico solo de batería es un recurso que Arias utilizó en Mi Vida Después con Carla. Agradezco a Natalia Fortuny esta observación. 


\section{"Nosotros decimos que las Malvinas son argentinas. Ellos que los isleños son ingleses" (o la soberanía como pregunta)}

"No quiero terminar la obra con un mensaje o con una afirmación (...) prefiero terminar con preguntas", dijo Arias en una entrevista pública realizada por Gonzalo Aguilar, luego de la función del 2 de diciembre del 2016 en el Centro de Artes Experimentales de la Universidad Nacional de San Martín. En realidad, toda la obra está atravesada por interrogantes, desde las demográficas dirigidas a los actores que recrean las audiciones en la escena inaugural (nombre, edad, rango y ocupación actual, por ejemplo), hasta las ético-políticas que interrogan el (sin)sentido de la guerra en la canción final compuesta y cantada en vivo por los propios veteranos. Campo Minado comienza y termina con preguntas explícitas que interpelan a los cuerpos dentro y fuera del escenario. La obra pregunta, asimismo, por la soberanía sobre las Islas. Más que reivindicarla, la cuestiona; más que disputarla, la sustrae. Y así, entre el cuestionamiento y la sustracción, mina lo que más contundentemente legitima a la guerra: la importancia de la soberanía nacional sobre las Islas para su propia trama de memorias sobre Malvinas.

Entre la directora y los actores decidieron poner la cuestión entre paréntesis: "Durante los ensayos entre los veteranos, no discutimos el problema de la soberanía sobre las Islas. Nosotros decimos que las Malvinas son argentinas, ellos, que los isleños son ingleses", dice Rubén Otero en el escenario. "La soberanía es algo de lo no dicho, o de lo que decidimos dejar afuera, porque [los excombatientes] no se iban a encontrar ahí," dijo Arias en la misma entrevista de 2016. La soberanía como pregunta, antes que como reclamo, no fue sin embargo una posición fácil o cómoda, exenta de resistencias. Desde el gobierno argentino hasta los propios actores y gente de Buenos Aires, impugnaban el gesto de fugarse de la disputa por la soberanía.

Cuando el proyecto contaba con apoyo financiero de festivales y otras instituciones británicas y europeas, Arias buscó una participación simétrica en la Argentina, pero no halló ningún apoyo en este país sino hasta que dio con el interés de la Universidad Nacional de General San Martín. Ministerios de gobierno y teatros oficiales rechazaron la idea de una obra de teatro sobre Malvinas que narraba la guerra "desde los dos lados" y evitaba el reclamo por la soberanía.

En algunas cartas de espectadores de teatro dirigidas a los veteranos, se leía incluso: "yo no me voy a sentar en el público a aplaudir a esos ingleses que mataron a nuestros hermanos". Y en la primera etapa del proceso dramatúrgico, de hecho, durante las entrevistas y audiciones iniciales, los propios actores no podían entender que participar en la obra, encontrarse en el escenario y "comprender el dolor, el sufrimiento y las experiencias del otro lado", no implicaba resignar el reclamo de soberanía sobre las islas. 
En una entrevista personal realizada el 12 de septiembre de 2017 a la autora, sin embargo, ésta narra cómo las resistencias se fueron disipando avanzados los ensayos. Actores, público y diversas asociaciones de excombatientes celebraron la decisión estético-política de no centrarse en la disputa por el dominio territorial sobre las Islas para esta creación escénica.

Pero para convivir en el conflicto hace falta expresarlo y para habitar el disenso es necesario visibilizarlo. Campo Minado no reivindica el dominio territorial sobre las Islas para la Argentina -y tampoco para Inglaterra-, no reclama la gestión del territorio isleño del Atlántico Sur para ninguna de las partes. Pero tampoco propone "un relato protopacifista que reúne a los opuestos y les imparte una fraternidad", tal como Martín Kohan (271) escribe a partir de la literatura sobre Malvinas. Campo Minado no le escapa a la hostilidad, el padecimiento o la pérdida ocurrida en nombre de la lucha por la soberanía nacional. No silencia ni esconde el trauma de una guerra legitimada en fronteras nacionales.

Paradójicamente, el capítulo llamado "Malvinas/Falklands" se aleja de todo emblema de nación. Dos veteranos argentinos abren la escena cantando el himno argentino a las Islas sin parodiarlo pero sin ninguna solemnidad. Inmediatamente se narran dos versiones, una "argentina", otra "inglesa", de la historia sociopolítica del territorio malvinense y, con excepción de Sukrin, cinco veteranos vociferan acusaciones recíprocas exponiendo desde crímenes de guerra (en que los ingleses atacaron a civiles violando la Cuarta Convención de Ginebra) hasta las torturas de combatientes argentinos por parte de sus propios oficiales. No simulan fraternidad ni universalismo alguno. Desnudan, en cambio, el absurdo y la desolación, el sinsentido y la congoja de toda guerra. Se gritan:

Aloja acusaciones mutuas soberan edes perdian la mor de Dios!"y mataron a tres mujeres civiles"oldados argentinos en itieron ir ¡A nosotros nos dijeron que ustedes no sabían por qué peleaban!

¡A nosotros nos dijeron que su gobierno mataba a su propia gente!

¡Ustedes nos cagaban a bombazos todos los fines de semana porque les pagaban más! ¡Cayó un helicóptero británico y ustedes dispararon a sus tripulantes cuando nadaban a la orilla para salvarse!

¡Ustedes hundieron al Belgrano fuera de la zona de exclusión!

¡Ustedes pusieron piezas de artillería en los jardines de civiles en Puerto Stanley!

¡Ustedes bombardearon por error a una casa en Puerto Argentino y mataron a tres mujeres civiles!

¡Ustedes izaron la bandera blanca en Goose Green, esperaron a que pasaran los soldados británicos y les dispararon por la espalda!

¡Ustedes remataban a los heridos en Monte Longdon!

¡Ustedes torturaban a sus propias tropas, por el amor de Dios! 
La obra se sustrae "del problema de la soberanía nacional" pero no oculta sus efectos sobre los cuerpos en la guerra, abriendo así el espacio para otras preguntas que revisan y recrean memorias sobre Malvinas. La libertad para distanciarse del pilar que sostiene simbólicamente a la guerra, abrió la posibilidad de socavarla, impugnando su sinsentido mediante preguntas. “¿Por qué digo 'yo' en lugar de 'nosotros'?”, pregunta David Jackson replanteándose quién habla (y quién tiene derecho a hacerlo) a través de sus propios relatos sobre el conflicto bélico de 1982. “¿Tengo el derecho a hablar en nombre de aquellos que fueron a la guerra y no volvieron? ¿Dónde están los muertos británicos en esta obra?", continúa. La ausencia deliberada de reclamos nacionales deja espacios de libertad para agitar interrogantes que resignifican la remembranza de la contienda. Fundamentalmente, se abren así espacios para rechazar la guerra toda y toda la tragedia de la guerra.

Es desde ese espacio de libertad que irrumpe la escena donde - los antes soldadosdevienen una poderosa banda de rock. Completada con una dulce poesía nepalí no traducida desde la boca de Sukrin, esta escena cierra la obra. Arias pidió a los actores que compusieran una canción "solo con preguntas" (Entrevista, 2017) para ser cantada por ellos mismos en vivo. Lou Armour, "cantante principal" de la banda de rock resultante (Jackson y Sagastume en guitarras eléctricas, Vallejo en el bajo y Otero en la batería), pregunta sobre los límites de lo que puede un cuerpo en la guerra. Nos obliga a meditar sobre la distribución horrorosamente arbitraria de vida y muerte, de lo que se protege y lo que se abandona en la guerra (y no solamente en ella):

¿Mandarías a tus hijos o tus hijas a la guerra? ¿Por qué pelearías? ¿La reina? ¿La patria? ¿Petróleo? ¿Alguna vez mataste a alguien? ¿Viste morir a alguien? ¿Alguna vez te sentiste ignorado por el gobierno que te mandó a la guerra? ¿Alguno de tus amigos se suicidó? ¿Alguna vez viste a alguien prendido de fuego? ¿Alguna vez viste a alguien ahogarse en el mar helado? ¿Alguna vez fuiste a la guerra?

Entre otras, estas preguntas interpelan a actores y a espectadores, a los cuerpos dentro y fuera del escenario. “¿Lo hiciste? ¿Lo harías?”, intercala la canción a modo de estribillo. No son enunciados de cualquier cuerpo, no provienen de un actor representando un papel, ¡son alaridos de cuerpos que vivieron y volvieron del campo de batalla! Son preguntas dirigidas a ellos mismos y dirigidas también a nosotros - espectadores- que en general poco sabemos de la guerra. Son preguntas que nos acercan a esa repartija absurda de formas de muerte que hace la guerra. Nos fuerzan a pensar sobre los límites de vida y muerte, que son el meollo mismo de la experiencia en la guerra. Nos obligan a pensar en nuestros límites, si estuviéramos - o no- en situación de guerra. 
La canción impugna la guerra sin moralizar ni distribuir rápida o fácilmente el bien y el mal; el honor y la humillación; los héroes, las víctimas y los villanos; lo propio y lo ajeno. Pues suspendido "el problema de la soberanía nacional" - el constructo que la legitima - nada impide rechazar la guerra toda. "Descubrí que nadie está preparado para la guerra", dijo Arias refiriéndose a los soldados ingleses entrenados profesionalmente y dispuestos a combatir en condiciones mucho más favorables que sus enemigos argentinos. Es que sabemos que más allá de la victoria o la derrota, no hay monopolio nacional para el trauma de la guerra.

\section{"Ese campo minado lo había puesto el Ejército Argentino..." (o a modo de conclusión)}

El nombre de la obra refiere, entre otras cosas, a un campo de batalla literalmente minado. Con la ayuda de Marcelo Vallejo manipulando pequeños objetos en una maqueta que se proyecta sobre el fondo del escenario, Gabriel Sagastume reconstruye la explosión de una mina personal en el Monte Wireless Ridge, que mató a cuatro de sus compañeros mientras volvían de robar comida. Un suboficial ordenó más tarde a Sagastume, entre otros, recoger los restos de los muertos y los heridos con sus propias frazadas. Sagastume reconoció la pierna de su compañero Vargas "porque usaba unas medias de fútbol con rayas de colores..." "Después nos enteramos", concluye él mismo al cierre de esa secuencia, "que ese campo minado lo había puesto el ejército argentino al principio de la guerra y nadie nos había avisado". Es esta escena la que nombra la obra, aludiendo al abandono de los cuerpos a la muerte - los "cuerpos propios", no los "cuerpos enemigos"- por parte de su propio Estado nacional.

Sin victimizarlo todo ni a todos, sin identificarse con la comunidad nacional pero sin privarse de la denuncia tampoco, la escena insiste en nombrar un Estado argentino que incumplió el contrato social que lo une al soldado-ciudadano. Campo Minado acusa a un ejército donde los oficiales son enemigos y torturadores de sus propios soldados, quienes están mal alimentados y abrigados, muy mal provistos de armamentos, desinformados y pésimamente entrenados para combatir.

Pero ese no es el único campo minado en la obra de Arias, como hemos visto. La puesta en escena mina también los ejes que suelen organizar las narraciones de Malvinas: no recupera héroes ni anti-héroes, no homenajea víctimas. Invita a excombatientes a convertirse en emprendedores de memoria, ${ }^{11}$ quienes, reconociendo el poder y los efectos que la nación

11 Jelin habla de "emprendedores de memoria" para enfatizar su capacidad de innovación y creatividad en la construcción de memorias y diferenciarlos de los "militantes de la memoria", tal vez más próximos a repeticiones ritualizadas $(48)$. 
inscribe en los cuerpos, no se identifican exclusiva o principalmente con ella. Pero tampoco se adscriben a una universalidad que adjudica hermandades banales y superfluas.

Como parte de lo que solo la ficción literaria puede lograr, diría Martín Kohan (El país), Campo Minado estalla los pilares que sostienen la guerra. Para este crítico, es sólo el terreno inaugurado por Fogwill con Los Pichiciegos el que es capaz de "desarticular lo nacional" y socavar esas nociones que - como las de "patria", "honor", "sacrificio" y "nación"- legitiman o al menos apuntalan la guerra; mientras que para el género testimonial eso resulta difícil. El testimonio no puede vaciar la tragedia de lo ocurrido en Malvinas, no puede dejar de denunciar las distintas atrocidades cometidas - desde la manipulación perpetrada por parte de la dictadura cívico-militar, hasta los crímenes de lesa humanidad cometidos-. De esta manera, agrega Kohan:

En el registro testimonial, por lo pronto, hay un límite muy difícil de franquear [...] se percibe un cierto consenso, y hasta podría decirse una cierta unanimidad, acerca de la legitimidad y la relevancia de la empresa de la recuperación de las islas, la vigencia prácticamente intocada de los credos de la argentinidad, con sus correspondientes vehemencias y sus correspondientes emociones, y la disposición manifiesta de volver a pelear por las islas en una guerra, siempre que se cuente con eso que en el 82 faltó: una preparación adecuada, una dirección inteligente, un pertrechamiento satisfactorio $(269-270)$.

En tanto teatro documental basado en testimonios, Campo Minado interrumpe ese consenso, descalabra "los credos de la argentinidad". No reclama soberanía nacional para ninguna de las partes y menos aún rescata algún valor en la recuperación argentina de las islas o en la disposición de volver a pelear en condiciones adecuadas. Pero tampoco sugiere una esencia humanista o una fraternidad capaz de transcenderlo todo. Se reserva el derecho a la denuncia sobre el poder y los efectos que las fronteras nacionales inscriben en los cuerpos. La obra reconoce las violencias y los padecimientos, las muertes y las pérdidas ocurridas en nombre de las luchas por la soberanía nacional. No evade el trauma de una guerra legitimada en los límites de la nación. Le da lugar a las acusaciones recíprocas, los reclamos opuestos y las legitimaciones rivales. Y desde ese campo minado, abre el espacio para preguntas-otras que impugnan la guerra toda, y todo el absurdo de la guerra. Desde ese campo minado, imagina una comunidad otra, sin esencias, lengua, religión ni nación en común. Surge un convivio multilingüe y plurinacional capaz de generar relatos y memorias sobre Malvinas atravesadas por la experiencia común y la vivencia semejante, pero también cargadas del disenso y del conflicto; memorias que recuperan el trauma de la guerra pero también la potencia para elaborarlo. 


\section{Bibliografía}

Arias, Lola. Entrevista personal con Verónica Perera. 12 de septiembre de 2017. Transcripción de archivo de audio.

Arias, Lola. Campo Minado. Festival de Brighton en Inglaterra de mayo de 2016. Arias, Lola. Mi vida después y otros textos. Buenos Aires: Penguin Random House, 2016. Arias, Lola. Entrevista pública con Gonzalo Aguilar. 2 de diciembre de 2016. (La entrevista se realizó a continuación de la función del 2 de diciembre en el Centro de Artes Experimentales de la UNSAM en Buenos Aires). Transcripción de archivo de audio. Arias, Lola, y Eliana Kan. "Lola Arias by Elianna Kan”. BOMB, no. 128, 2014, pp. 58-64. Fogwill, Rodolfo. Los Pichiciegos. Buenos Aires: Interzona, 2012.

Gamerro, Carlos. Las Islas. Buenos Aires: Edhasa, 2012.

Guber, Rosana. ¿Por qué Malvinas? Buenos Aires: Fondo de Cultura Económica, 2001. Halbwachs, Maurice. La memoria colectiva. Buenos Aires: Miño y Dávila, 2011. Jelin, Elizabeth. Los trabajos de la memoria. Madrid: Siglo xxi Editores, 2002.

Kohan, Martín. El país de la guerra. Buenos Aires: Eterna Cadencia, 2014.

Perera, Verónica y Diz, María Luisa. "Memorias del pasado reciente: la guerra de Malvinas en el teatro independiente". Jornadas de Estudios sobre el Teatro Independiente, Centro Cultural de la Cooperación Floreal Gorini. 22 y 23 de septiembre de 2016, Buenos Aires. Ponencia.

Sabugal Paz, Paulina. “Teatro Documental: entre la realidad y la ficción”. Investigación Teatral, vols. 6-7, números 10-11, 2016, pp. 111-129.

Weiss, Peter. Escritos políticos. Barcelona: Editorial Lumen, 1976. 